Post-print of Llorach-Massana, Pere et al. «Analysis of the technical, environmental and economic potential of phase change materials (PCM) for root zone heating in Mediterranean greenhouses» in Renewable Energy (ScienceDirect). Vol. 103 (April 2017), p. 570-581. The final version is available at DOI 10.1016/j.renene.2016.11.040

\title{
Analysis of the technical, environmental and economic potential of phase change materials (PCM) for root zone heating in Mediterranean greenhouses.
}

\author{
Pere Llorach-Massana ${ }^{a, b}, *$, Javier Peña ${ }^{b}$, Joan Rieradevall ${ }^{a, c}$, Juan Ignacio Montero ${ }^{d}$ \\ a Sostenipra Research Group (SGR 01412), Institute of Environmental Sciences and Technology (ICTA), Z Building, Universitat \\ Autònoma de Barcelona (UAB), Campus UAB, 08193 Bellaterra, Barcelona, Spain \\ ${ }^{\mathrm{b}}$ ELISAVA Barcelona School of Design and Engineering. La Rambla 30-32. 08002 Barcelona (Spain) \\ 'Department of Chemical Engineering, biological and Environmental, School of Engineering, Building Q, Universitat Autònoma de \\ Barcelona (UAB), 08193 Bellaterra, Barcelona, Spain. \\ dinstitute of Food and Agricultural Research (IRTA), Carretera de Cabrils, km 2, 08348 Barcelona, Spain \\ *Address: Z Building, Universitat Autònoma de Barcelona (UAB), Campus UAB, 08193 Bellaterra, \\ Barcelona, Spain \\ Tel.: (+34) 93.586.86.45 \\ E-mail: pere.llorach@uab.cat
}

\begin{abstract}
Root zone heating systems offer increasing crops quality and productivity. However, these systems are based on the use of nonrenewable fuels. This paper reports on a study of different design solutions for a root zone heating system, based on thermal energy storage with PCM. The objective of the study was to define, through multiple experiments, the most efficient PCM melting/freezing temperature and location with respect to the substrate (i.e., under the substrate) for the application under study; as well as, to determine the system's environmental and economic feasibility, with life cycle assessment and life cycle cost methodologies. Results show that the best melting temperature for the application under study is $15^{\circ} \mathrm{C}$. To increase the efficiency of the system, PCMs may be macro encapsulated and wrap the entire perlite bag. Moreover, it seems that PCMs are far to substitute conventional root zone heating systems because it does not provided enough heat during nights. Nevertheless, PCMs can help to reduce the operation time of conventional systems. Based on one night results it seem that PCM could provide annual saving of between $22-30 \mathrm{~kg}$ of eq. $\mathrm{CO}_{2} /$ ha $\cdot$ day. However, it does not seem to be feasible if PCM prices $(8 € / \mathrm{kg})$ do not decrease significantly.

\section{Keywords}

Phase Change Materials (PCM) / Root zone heating / Soilless crops / Environmental assessment / Economic assessment

\section{Highlights}

- The thermal behavior of a perlite bag from a Mediterranean soilless protected crop is described.

- A TES system with PCM to heat plants roots in soilless crops is studied with multiple experiments.

- The best PCM phase change temperature for the application seems to be $15^{\circ} \mathrm{C}$.

- The most effective PCM location consists of wrapping the perlite bag.

- 20-30 Kg of eq. $\mathrm{CO}_{2}$ emissions could be saved per hectare and night.
\end{abstract}




\begin{tabular}{|c|c|c|c|}
\hline \multicolumn{4}{|c|}{ Abbreviations \& nomenclature } \\
\hline PCM & phase change material & $Q_{15^{\circ} \mathrm{C}}$ & heat required to maintain the \\
\hline TES & thermal energy storage systems & & conventional perlite bag at $15^{\circ} \mathrm{C}$ \\
\hline LDPE & low density polyethylene & $Q_{P C M}$ & heat provided by the PCM to the \\
\hline$C_{p}$ & perlite specific heat $\left(0,387 \mathrm{~kJ} / \mathrm{kg} \cdot{ }^{\circ} \mathrm{C}\right)$ & & perlite bag \\
\hline$C_{H 2 O}$ & water specific heat $\left(4.18 \mathrm{~kJ} / \mathrm{kg} \cdot{ }^{\circ} \mathrm{C}\right)$ & $T_{15^{\circ} \mathrm{C}}$ & constant $15^{\circ} \mathrm{C}$ temperature \\
\hline$E_{s}$ & energy savings & $T_{\text {control bag }}$ & control's bag temperature \\
\hline$m_{p}$ & perlite mass & $T_{P C M ~ b a g}$ & bag with PCM's temperature \\
\hline$m_{H 2 O}$ & water mass & & \\
\hline$v_{p c m}$ & PCM volume & $P_{R H}$ & Power of root heating \\
\hline$\lambda_{p c m}$ & PCM enthalpy & $L_{b a g}$ & Length of the perlite bag ( $1 \mathrm{~m})$ \\
\hline$\rho_{p c m}$ & PCM density in solid state & $t$ & Time \\
\hline
\end{tabular}

46

47

\section{Introduction}

\subsection{Greenhouse heating systems based on TES systems with PCM}

Thermal energy storage (TES) systems allow the storage of large amounts of cold or heat for long periods of time (hours, days or month) and recover the heat when required. Phase change materials (PCM) have been used to create different TES applications, e.g., for buildings [1-3], waste heat collectors [4] or storage and transportation cooling systems [5]. PCM are substances with a high heat of fusion and specific melting and solidifying temperatures and can be used for storing and releasing large amounts of thermal energy. PCM can be used to store solar energy during the day and release it at night.

PCM applications are of great interest due to the capacity of PCM to increase systems' energy efficiency and reduce their dependence on nonrenewable resources. Few PCM applications have been designed to improve greenhouse heating systems [6-11]. These applications aim to reduce greenhouse heating system energy consumption by (1) using solar collectors inside [6] or outside [9] the greenhouse based on PCM use, (2) installing a ground-source heat pumpphase change material for latent heat storage system in greenhouses [7], (3) increasing the energy efficiency of heat pumps with new PCM applications [8], (4) using PCM to reduce daily temperatures without the use of cooling systems [10], or (5) installing a north wall made of PCM inside the greenhouse as a TES [11].

\subsection{PCM application for root zone temperature control}

Providing proper temperatures to the root of crops stimulates plants development and flowers production, which results in an increase of productivity [12]. Yasushi et al. [13] compared the production yield of a tomato crop without a root zone temperature control system and a crop during which nigh root temperatures were maintained over $15^{\circ} \mathrm{C}$ by using a root heating system (no air heating was used). The yield of the heated crop was $20 \%$ higher and its fruits were $30.5 \%$ heavier. Another study [14] detected for tomato crops a decrease of flower production and a reduction of fruit weight when ambient temperatures increase above $25^{\circ} \mathrm{C}$ or decrease under $15^{\circ} \mathrm{C}$. Therefore, it seems that tomato plants ideal root and ambient temperatures to enhance productivity may be maintained between $15^{\circ} \mathrm{C}$ and $25^{\circ} \mathrm{C}$. Root zone heating can be combined with air heating [15]; nevertheless, heating specifically the root zone can reduce fuel consumption rather than heating the air of the greenhouse [16]. 
Some authors have looked for the ideal root temperatures for other crops. For example, has already been reported that a proper root temperatures for lettuces production could be between 17 and $24^{\circ} \mathrm{C}$ [17]. For the case of maize production no significant effects were detected in plants and productivity if root temperatures are maintained between $13^{\circ} \mathrm{C}$ and $28^{\circ} \mathrm{C}$ [18]. For other crops such as tobacco, cotton, corn or pea ideal root temperatures may be $32^{\circ} \mathrm{C}, 25^{\circ} \mathrm{C}, 20^{\circ} \mathrm{C}$ and $10^{\circ} \mathrm{C}$, respectively [19]. Therefore, ideal root temperatures are different for each plan.

Root zone temperature control has been conventionally achieved with expensive and unsustainable gas and oil heating systems. Some PCM systems to control root zone temperature have been studied as a means to improve the environmental performance of crop production systems while ensuring the increase of crop production. An actual experience with PCM for root zone temperature control was found in the literature [20]. The study testes, with positive results, two $\mathrm{PCM}$ with a similar phase change temperature of $12^{\circ} \mathrm{C}$ in soilless protected crops in Turkey. In this case, PCM were located next to the perlite bags. The manuscript concludes that further research is required to investigate PCMs with other thermal properties and different encapsulation shapes. In addition, they suggest that most of the thermal energy stored by the PCM was lost by convection to the air at night, fact that reduced the efficiency of the system.

Another study analyses the environmental and economic feasibility of a theoretical application of PCM, in a greenhouse with 19.4ha from southern Spain, as a substitute to conventional root zone heating systems which use oil, gas or biomass boilers [21]. This study concludes that PCM seem to be a potential technology to substitute conventional heating systems and provide environmental and economic benefits. Nevertheless, it is based on detailed calculations and not real data. For this reason the manuscript concludes that there is the need generate and use real data to reduce the uncertainty of its results.

\subsection{Soilless culture and substrates.}

Some studies have concluded that soilless culture is the most intensive and effective production system in the agricultural industry $[22,23]$. Soilless culture is based on systems which allow plant growth without the use of soil as growing medium. Plants can be grown in porous substrates or directly in contact with water without the use of substrates. In soilless crops the exact nutrients required by plants are mixed supplied through the irrigation water [24], making these crops efficient in terms of water and nutrients per $\mathrm{kg}$ of production.

Substrates used in soilless culture can be divided in two groups: organic (i.e. coconut fibers, wood residues, bark, rice hulls) or inorganics (roockwool, sand, perlite, pumice). Inorganics have the advantage of being free of potential diseases, pests and weed seeds. Moreover, they drain better than organics, fact that allow a better control of soil conditions (i.e. nutrients content, available water for plants) [25].

In Spain and the Mediterranean area, it is common the use of perlite as a substrate in soilless crops. In fact, in Southern Spain, where is concentrated nearly all greenhouse tomato production in Spain (Spain produced 3.68t of tomato in 2013 [26]), perlite is a common substrate used. Despite the importance of its use and the relevance of root zone temperatures on yield production $[12,13]$, the thermal behavior of such substrate in protected crops has not been properly defined. 
Root heating systems combined for soilless crops with perlite substrates can increase significantly production yield with an efficient use of water and fertilizers. However, it is still required further research to determine the thermal behavior of perlite bags and how root zone heating systems can be environmentally improved with the use of PCM. For these reasons, this essay seeks to (1) describe the thermal behavior of a conventional perlite bag which has not been sufficiently described in the literature; (2) select the most effective position for the PCM in relation to the cropping bag (i.e., under, next to, wrapping the bag) to minimize root zone temperature decrease at night; (3) determine the best PCM melting/freezing temperature for its application in Mediterranean greenhouses; and (4) quantify the carbon footprint and economic savings that PCM could provide over conventional gas, oil or biomass root zone heating systems.

\section{Methodology}

\subsection{Experimental area and crop}

The study was completed in a greenhouse situated in Cabrils, north Barcelona (Latitude: $41^{\circ}$ $31^{\prime} 2.6^{\prime \prime} \mathrm{N}$, Longitude: $2^{\circ} 22^{\prime} 39.3^{\prime \prime} \mathrm{E}$ ) under a Mediterranean climate. The greenhouse was $19.2 \mathrm{~m}$ wide and $12 \mathrm{~m}$ long, with a $3 \mathrm{~m}$ high gutter and a $5.5 \mathrm{~m}$ high ridge, covered with a single PE layer opaque to far infrared radiation. Average, minimum and maximum temperatures for each season during 2014 in Cabrils are provided in Table 1 [27]. In this region, average and minimum temperatures between November and March (Figure 1) can be low enough to compromise crop continuity. Moreover, the use of root zone heating systems is not commonly used in the region, due to economic infeasibility. Consequently, crop production is finished when temperatures drop during November. PCM root zone applications could help ensure crop production continuity during cold periods or extend crop production during November and allow earlier crop initiation in March. The present study was developed with a tomato crop (solanum lycopersicum Arawak) for which the ideal root zone temperatures to maximize production were considered to be between $15^{\circ} \mathrm{C}$ and $25^{\circ} \mathrm{C}$.

¡Error! No se encuentra el origen de la referencia.Table 1. Average, maximum and minimum temperatures for each season in Cabrils (Barcelona, Spain) during 2014 [27]

\begin{tabular}{lcccc}
\cline { 2 - 5 } & \multicolumn{4}{c}{ Cabrils (2014) } \\
\cline { 2 - 5 } & Winter & Spring & Summer & Autumn \\
\hline Avg. Temperature $\left({ }^{\circ} \mathrm{C}\right)$ & 11.0 & 17.0 & 23.4 & 16.3 \\
\hline Max. Temperature $\left({ }^{\circ} \mathrm{C}\right)$ & 23.1 & 32.9 & 30.3 & 26.4 \\
\hline Min. Temperature $\left({ }^{\circ} \mathrm{C}\right)$ & 1.6 & 4.6 & 15.4 & 4.2 \\
\hline
\end{tabular}




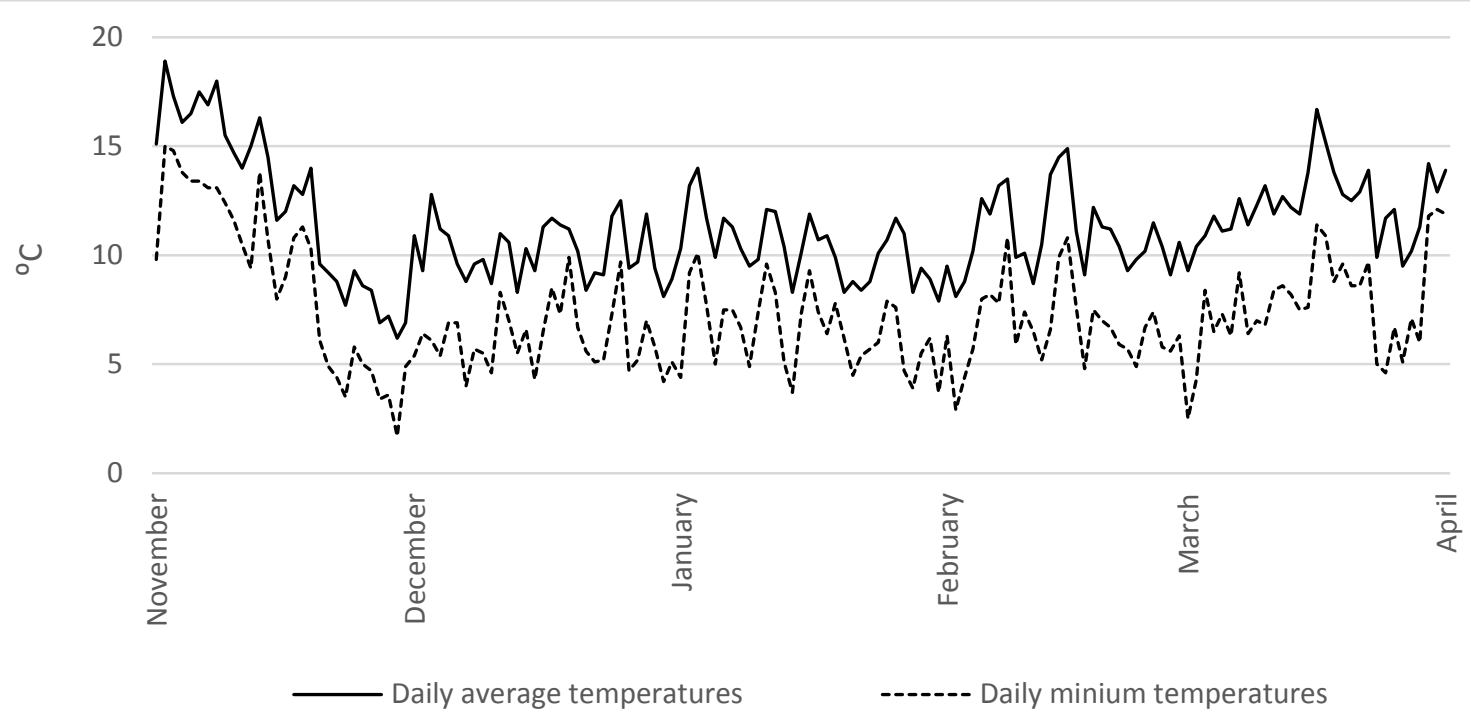

Figure 1. Daily average and minimum temperatures between November 2013 and March 2014 [27]

\subsection{Thermal behavior of a conventional perlite bag}

The cropping bag used for the experiment was made of low-density polyethylene (LDPE) film and contained perlite B12, with a thermal conductivity of $0.035-0.045 \mathrm{~W} / \mathrm{Km}$. The total volume of the bag was approximately of $47 \mathrm{~L}(100 \times 28 \times 17 \mathrm{~cm})$. Inner temperatures of the bag were measured during one sunny week with 5 Campbell Scientific 107 temperature probe thermistors with an accuracy of $+/-0.1^{\circ} \mathrm{C}$, to define the thermal behavior of this perlite bag. Thermistors were distributed in axis " $X$ " and " $Y$ " as Figure 2 shows.

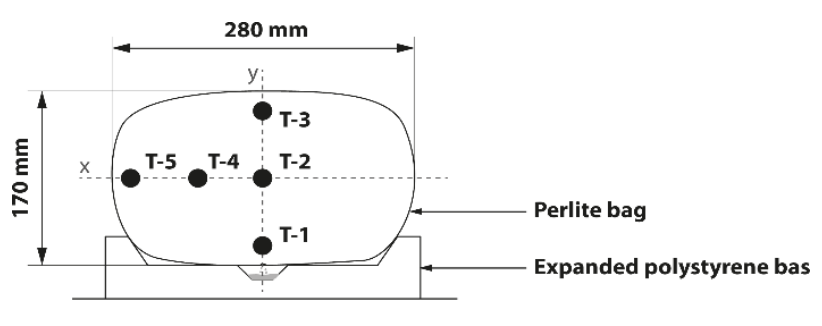

Figure 2. Schematic diagram of T-type thermocouple distribution for temperature measurements in a perlite bag. 
Table 2. Description of the experiments used for the study

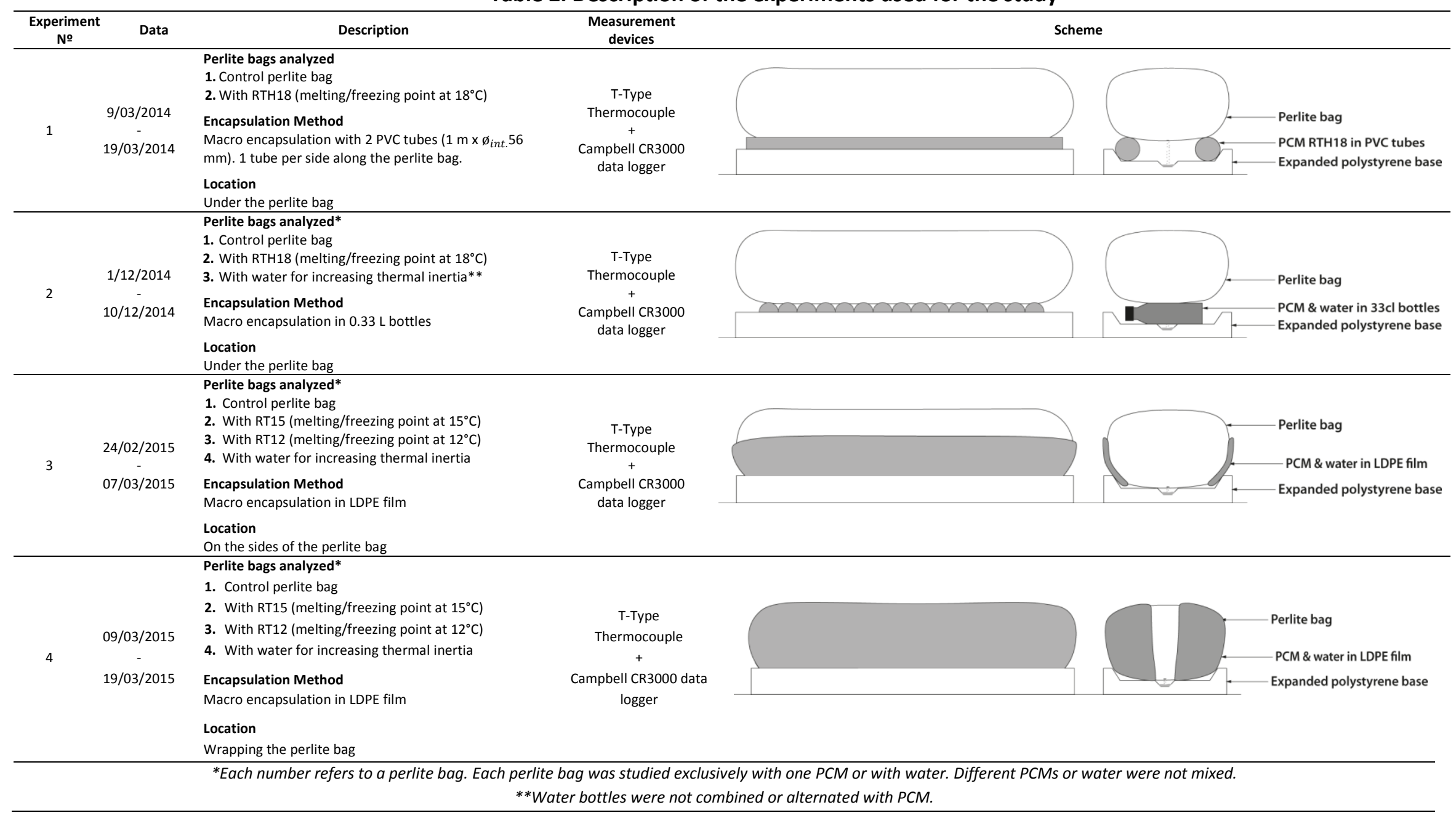


2.3. Selecting the best PCM location in relation to the perlite bag and determining the ideal PCM melting/freezing temperature.

Four experiments were completed for this part of the study (Table 2):

\section{-Experiment 1: PCM inside PVC tubes under the perlite bag}

-Experiment 2: PCM in $0.33 \mathrm{~L}$ polyethylene bottles under the perlite bag

-Experiment 3: PCM macro encapsulated in LDPE bags wrapping the bottom of the perlite bag. -Experiment 4: PCM macro encapsulated in LDPE bags wrapping the whole perlite bag.

All experiments were conducted during cooler periods in the Mediterranean (between November and March 2014-2015, which is when substrate heating is required). The results and conclusions obtained from one experiment were used to define the next experiment. For each experiment the temperature was measured in the center of the perlite bags, where the axis $x$ and $y$ in Figure 2 cross. Additionally, temperature measurements in a control perlite bag were collected in all experiments. The measurements were made with Campbell Scientific 107 temperature probe thermistors. Average values were collected every 10 minutes with a CR3000 data logger. The period of each experiment, the PCM used and the location of the PCM in relation to the perlite bag are specified in Table 2. In all case studies, the volume of PCM used per each perlite bag was 6 liters.

The volume of the PCM required for the experiment was determined by the following formula:

$$
v_{p c m}=\frac{\frac{P_{R H}}{\lambda_{p c m}} \cdot L_{\text {bag }} \cdot t}{\rho_{\text {pcm }}}
$$

where $v_{p c m}, \lambda_{p c m}$ and $\rho_{p c m}$ are the volume, enthalpy and density in solid state of the PCM, respectively. $P_{R H}$ refers to the power that the heating system, that is to say the PCM, may provide to the perlite bag. It was assumed that this value should be of $20 \mathrm{~W} / \mathrm{m}$ as in conventional root zone hating systems [28]. $L_{b a g}$ is the length of the perlite bag and $t$ is the equivalent time that a conventional heating system may operate in cool periods in the greenhouse were experiments were developed. In this greenhouse temperatures usually get lower than $15^{\circ} \mathrm{C}$ between 0:00 and 10:00. For this reason was assumed that PCM may provide the equivalent energy to a system that was operating during $10 \mathrm{~h}$. The calculation was first elaborated for the PCMs with the lower enthalpies RT12 (150kJ/kg) [29] RT15 (140kJ/kg) [30] (table 3). Volumes calculated were 5.5 and 5.8 liters, respectively. We decided to use 6 liters to oversize the design and ensure that PCM had the potential to provide enough energy to the perlite bag.

For the case of PCM RT18HC [31], with an enthalpy of $250 \mathrm{~kJ} / \mathrm{kg}$ the mass that should be used according to the formula was 3.3 litters. It was not enough volume to distribute the PCM through the whole perlite bag length. Then, we decided to use 6 liters of RT18HC PCM as for the other PCMs. The use of 6 liters of PCM instead of the 3.3 liters calculated increases the heat storage capacity of the system. Therefore, it should be taken into account that if thermal benefits when using this PCM are higher than when RT12 and RT15 are used is because the highest enthalpy of the PCM RT18HC.

The use of water (macro encapsulated in the same way as PCM) to increase the thermal inertia of the perlite bags as a potential solution to control root zone temperatures was also tested during experiments 2, 3 and 4 . For these tests, 12 liters of water were used per each perlite 
bag. The sensible heat of water at $20^{\circ} \mathrm{C}\left(4.18 \mathrm{~kJ} / \mathrm{Kg} \cdot{ }^{\circ} \mathrm{C}\right)$ is very low in comparison with the latent heat of PCM. For this reason the volume of water used was maximized as much as possible according to the maximum volume that the encapsulation method allowed. Despite it could has been interesting to use a higher volume of water, which could provide the same energy storage capacity than the PCM, the encapsulation method limited this volume up to 12 liters. Water was respectively encapsulated in the same way that PCMs were encapsulated in each experiment. Water was never mixed with PCMs, just as the PCMs were never mixed between them. It should be noted that large-scale purchases price per kg of PCM used in this study was $8 € / \mathrm{kg}$. Considering this, the use of water as a TES system could present important economic advantages.

For the first experiment, the location of the PCM in relation to the perlite bag was selected according to the discussion presented by Beyza Beyhan et al. [20]. This paper mentioned that " $40-80 \%$ of stored heat was lost to the surrounding and not transferred to the substrate". The authors consider that this loss was likely the result of insufficient surface contact between the substrate and the PCM. Therefore, we elected to situate the PCM under the perlite bag. PVC tubes were used as an encapsulation method due to their low cost and ease of installation under the substrate. We decided to use two PVC tubes (under the perlite bag one on the right side and one on the left side) because they allow a proper drain of the perlite bag as can be seen experiment 1 picture from table 2 .

Beyza Beyhan et al. [20] selected the melting/freezing PCM temperature based on the minimum temperature levels required to avoid stress in plants: $10-15^{\circ} \mathrm{C}[20,32]$. However, to avoid achieving $15^{\circ} \mathrm{C}$, the $\mathrm{PCM}$ melting/freezing temperature was set higher than the mentioned temperature. Consequently, a PCM with a melting temperature of $18^{\circ} \mathrm{C}$ was selected for the first experiment (Table 2). For experiments 2, 3 and 4, PCMs were selected according to the results obtained from experiment 1 . Table 3 shows the properties of the PCM used for the study. These PCM were selected based on the following:

- Rubitherm products, specifically RT18HC, were considered as potential PCM for root zone temperature control based on theoretical environmental and economic assessments previously completed [21].

- Organic PCM were used due to their recycling potential due to the environmental approach of the study.

- Phase change temperature was the main requirement for selecting PCMs, with enthalpies being considered less relevant according to the objectives of the study. The aim of the study was to determine whether PCMs were melting or not during cold periods in a Mediterranean greenhouse.

- Rubitherm PCMs were used due to the availability of the products for the research.

Table 3.PCM RT12 [29], RT15 [30] and RT18HC [31] thermal properties according to Rubitherm data sheets .

\begin{tabular}{cccccc}
\cline { 2 - 5 } & \multicolumn{4}{c}{ PCM Properties } \\
\cline { 2 - 5 } & RT12 & RT15 & RT18HC & Units \\
\hline Main peaks congealing/melting area & 12 & 15 & 18 & ${ }^{\circ} \mathrm{C}$ \\
\hline Melting area & $7-13$ & $10-17$ & $17-19$ & ${ }^{\circ} \mathrm{C}$ \\
\hline
\end{tabular}




\begin{tabular}{ccccc} 
Congealing area & $13-6$ & $17-10$ & $19-17$ & ${ }^{\circ} \mathrm{C}$ \\
\hline Enthalpy & 150 & 140 & 250 & $\mathrm{~kJ} / \mathrm{kg}$ \\
\hline Heat conductivity (both phases) & 0.2 & 0.2 & 0.2 & $\mathrm{~W} /(\mathrm{m} \cdot \mathrm{K})$ \\
\hline Volume expansion & 12.5 & 12.5 & 12.5 & $\%$ \\
\hline Max. Operation temperature & 55 & 50 & 40 & ${ }^{\circ} \mathrm{C}$ \\
\hline Density (sloid state) & 0.88 & 0.88 & 0.88 & $\mathrm{Kg} / \mathrm{l}$ \\
\hline
\end{tabular}

\subsection{Potential energy, environmental and economic savings}

This part of the study aimed to estimate the potential energy, environmental and economic savings that the application under study could provide to soilless crops for a single night. For this calculation, the specific PCM phase change temperature and location were selected from Table 2 to provide the highest thermal energy benefits to the perlite bag. Then, the following data were calculated: (1) the energy required to maintain the control perlite bag at $15^{\circ} \mathrm{C}$ (temperature required to avoid stress on plants [32]); (2) the thermal energy that the selected experiment (with specific phase change temperature and location) provided to the perlite bag; and (3) the potential energy, environmental and economic savings that PCM could provide to a system that uses root zone heating to maintain perlite bag temperature at $15^{\circ} \mathrm{C}$.

The following formula was used for the first calculation:

$$
Q_{15^{\circ} \mathrm{C}}=\left(m_{p} \cdot C_{p}+m_{H 2 O} \cdot C_{H 2 O}\right) \cdot\left(T_{15^{\circ} \mathrm{C}}-T_{\text {control bag }}\right)^{[2]}
$$

For the second calculation, an adaptation of the same formula was used:

$$
Q_{P C M}=\left(m_{p} \cdot C_{p}+m_{H 2 O} \cdot C_{H 2 O}\right) \cdot\left(T_{P C M ~ b a g}-T_{\text {control bag }}\right)^{[3]}
$$

where $m_{p}$ is the mass of the perlite of the bag $(3.58 \mathrm{~kg})$ and $m_{H 2 O}$ is the mass of water. According to Orozco et al. [33], for a perlite B12, which is the type of perlite used for the experiment, a water management program (intended for tomato production) was selected so the perlite bag contained at least $45 \%$ water. The perlite bag had a volume of $47 \mathrm{~L}$; therefore, the content of water in the perlite bag was assumed to be $21.2 \mathrm{~L}(21.2 \mathrm{~kg}) . C$ is the specific heat of both perlite $\left(0,387 \mathrm{~kJ} / \mathrm{kg} \cdot{ }^{\circ} \mathrm{C}\right)$ and water $\left(4.18 \mathrm{~kJ} / \mathrm{kg} \cdot{ }^{\circ} \mathrm{C}\right) \cdot T_{P C M}$ is the temperature of the perlite bag with PCM; and $T_{\text {control }}$ is the temperature of the control bag. $T_{15^{\circ} \mathrm{C}}$ represents the constant temperature value of $15^{\circ} \mathrm{C}$.

To estimate the potential energy savings $\left(E_{S}\right)$ that $\mathrm{PCM}$ could provide to a root zone heating system, the following ratio was calculated: $E_{S}=Q_{P C M} / Q_{15^{\circ} C}{ }^{[3]}$.

Finally, the operation equivalent $\mathrm{CO}_{2}$ emissions and fuel costs to maintain the control bag at $15^{\circ} \mathrm{C}$ using a root zone heating system with gas, oil and biomass boilers with efficiencies of $90 \%, 91 \%$ and $87 \%$, respectively, were calculated, according to the previously completed environmental assessment [21]. Additionally, the equivalent $\mathrm{CO}_{2}$ emissions and costs that could be avoided if PCM were used as a solution to increase conventional root zone heating systems efficiency were accounted for.

The calculation of the mentioned equivalent $\mathrm{CO}_{2}$ emissions were based on the Life Cycle Assessment methodology, according to ISO 14040 [34]. Only emissions from operation phase were considered, avoiding emissions from infrastructure (i.e., the boiler; HDPE tubes for the 
heating system). Data for the calculation were obtained from the Ecoinvent 2 database, using Simapro7 as the support program. The calculation method used was Recipe $(\mathrm{H})$ and the impact category analyzed was Climate Change (kg $\mathrm{CO} 2$ eq.). The gas prices were based on a local provider [35], oil prices were obtained from the "Spanish Institute for Diversification and Energy Saving" [36] and the price for biomass was obtained from the "Spanish Association of Energy Recovery" [37].

Energy, environmental and economic savings showed in results must be understood as potential savings. Results are based on one night thermal benefits of PCMS. Therefor there is some uncertainty that should be assumed. Nevertheless, these give a first idea of the possible benefits of the technology which can be useful to determine how this technology should evolve in the future.

\section{Interpretation of results and discussion}

\subsection{Thermal behavior of a conventional perlite bag}

The results are shown in two separate graphs (Figure 3 ) by grouping results from thermistors situated in axis $x$ (T-1; T-2; T3) and $y(\mathrm{~T}-2 ; \mathrm{T}-4 ; \mathrm{T}-5)$ according to locations defined in Figure 2 . In addition, Figure 4 shows a scheme of the daily temperature pattern based on the experimental measurements.
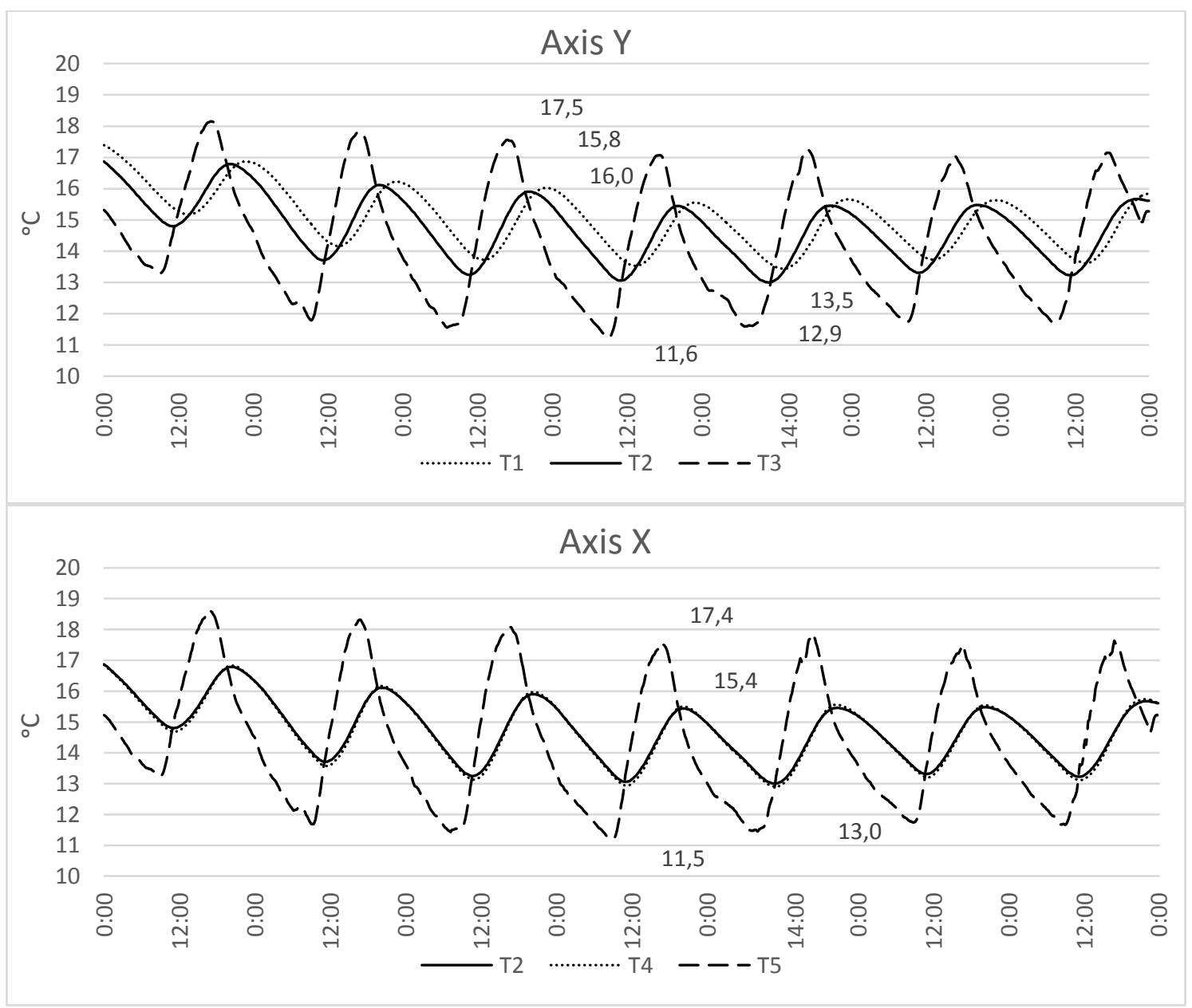

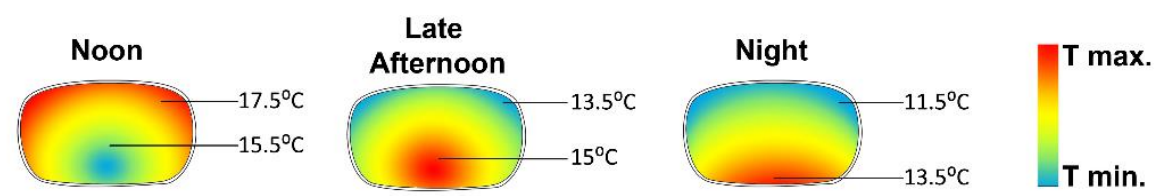

$\mathbf{T} \max$.

Figure 4. Scheme of a perlite bag's temperature pattern during a sunny day during the early cold period (color scale is a relative temperature scale and is different for each period). This figure summarizes results from figure 3 .

As shown in Figures 3 and 4, the temperatures in the perlite bag before sunrise were similar at the bottom and the center but slightly higher at the bottom $\left(0.5^{\circ} \mathrm{C}\right)$. The external parts of the bag (top, right and left) were $1.5^{\circ} \mathrm{C}$ lower than those at the center. Greenhouse and perlite bag temperatures increased at noon due to solar radiation. At this time, the outer zone of the bag was hotter (almost $2^{\circ} \mathrm{C}$ ) than the inner zone, which was still cold due to the low temperatures achieved throughout the night. At noon and during midday, the perlite bag accumulated sensible heat. By late afternoon, after sunset, the perlite bag registered the heat absorbed during the day. Consequently, the inner zone of the perlite bag was hotter $\left(1-1.5^{\circ} \mathrm{C}\right)$ than the outer zone. At night, temperatures in the perlite bag tend to stabilize. However, the bottom of the bag was hotter than the rest of the bag $\left(2^{\circ} \mathrm{C}\right)$. This situation may have occurred for two reasons: (1) the bottom of the perlite bag was not in direct contact with greenhouse air, and consequently there was no convection in this part of the bag; and (2) the expanded polystyrene base used to collect the leachates helped increase the thermal isolation of the substrate. At the end of the night, before the sunrise, temperatures at the bottom were still significantly higher $\left(1.5^{\circ} \mathrm{C}\right)$. The delay of $\mathrm{T} 1$ in figure 3 in axis $\mathrm{Y}$ in relation with $\mathrm{T} 2$ is explained by the fact that T1 (bottom of the perlite) bag is less influenced by ambient temperature than the center of the bag (T2). It can be explained by the fact that the bottom of the bag is isolated by the polystyrene base and influenced by the thermal inertia of the ground. Then T1 requires more time to get warmer and later it keeps heat better than the rest of the perlite bag.

\subsection{Selecting the best PCM location in relation to the perlite bag and determining the ideal PCM melting/freezing temperature.}

In this section, the results for each experiment are presented separately. However, the relations between experiments, which describe the iterative process used, are addressed. A representative day is shown for each experiment to facilitate comparisons between experiments. 
354
$28 / 03 / 2014$ 28
27
26
25
24
23
22
21
20
19
18
17
16
15
14
13
12
11
10

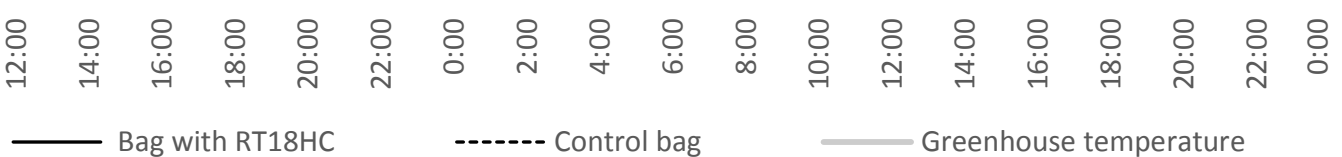

Figure 5. Diurnal temperature measurements of a root zone passive heating system with PCM RT18HC macro encapsulated in PVC tubes, a control perlite bag and inner greenhouse temperatures. Perlite temperatures were measured at the center of the bags.

Experiment 1 (Table 2) tested a root zone passive heating system with PCM RT18HC (Table 3) macro encapsulated in PVC tubes located under the perlite bag. Few thermal benefits were observed during the experiment. For the best day, a $0.7^{\circ} \mathrm{C}$ difference between the temperatures of the RT18HC bag and the control perlite bag was achieved (Figure 5). However, there was no consistent repetition or continuity in the results. For some nights with similar greenhouse temperatures, the perlite bag with added PCM had temperatures that were equal to or lower than those of the control bag.

Because of the opacity of the PVC tubes used and the lack of continuity in the results, it was not evident that the PCM was melting and freezing. Moreover, the $1.8 \mathrm{~mm}$ thickness of the PVC and the PVC's low thermal conductivity were limiting aspects that reduced thermal transmission between the PCM, the air and the perlite bag.

\subsubsection{Experiment 2: PCM RT18HC macro encapsulated in $0.33 \mathrm{~L}$ water bottles}

To visually control the PCM used (visualize liquid or solid phase) and to reduce the thickness of the encapsulation system, PVC tubes used in Experiment 1 were substituted by $0.33 \mathrm{~L}$ water bottles (Table 2). Moreover, in Experiment 2 and the following experiments the potential of water as a root zone heating system by increasing the storage of sensible heat of the perlite bags during the day was analyzed. Consequently, in Experiment 2 three perlite bag temperatures were controlled: (1) root zone heating system with CPM RT18HC; (2) root zone heating system with water to increase sensible heat storage; and (3) a control perlite bag. 


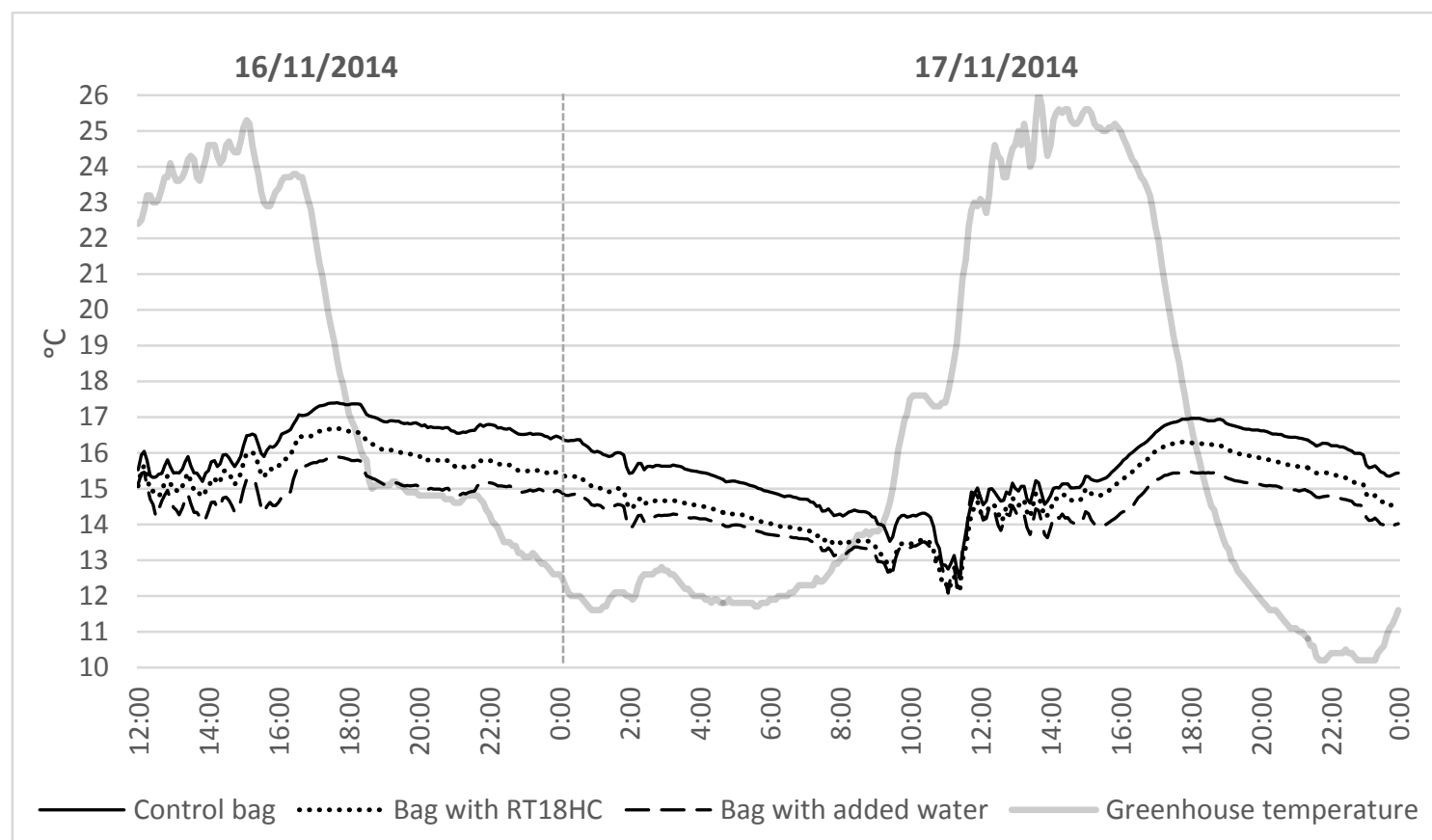

Figure 6. Diurnal temperature measurements of a (1) control perlite bag; (2) a root zone passive heating system with PCM RT18HC macro encapsulated in $0.33 \mathrm{~L}$ water bottles; (3) a root zone passive heating system with water macro encapsulated in $0.33 \mathrm{~L}$ water bottles; and (4) inner greenhouse temperatures. Perlite temperatures were measured at the center of the bags.

As Figure 6 shows, no nighttime thermal benefits were obtained in Experiment 2. Bags with added water and PCM had lower temperatures than the control bag both during the day and at night. This phenomenon has two possible explanations: (1) perlite bags were raised when bottles are introduced at the bottom; consequently the perlite bag's ventilation was improved during the day; and (2) the PCM and water applications increased the sensible heat capacity of the perlite bag, reducing the temperature oscillations between night and day. It was visually confirmed that PCM RT18HC was not likely melting during the day. The increased perlite bag temperatures were not high enough to cause melting. Consequently, the PCM likely experienced no melting, as in Experiment 1.

\subsubsection{Experiment 3: Water, PCM RT15 and 12 wrapping the bottom of the perlite bag.}

Experiment 1 and 2 revealed that the selected melting freezing temperature of PCM RT18HC was too high for the application. Consequently, for Experiment 3 PCM with two lower melting temperatures were selected: RT12 and RT15 (Table 3). The use of water as a system to increase perlite bag sensible heat capacity was also studied in this experiment. The location of the added elements for Experiment 3, wrapping the bottom of the bag, was selected with the intention of increasing the surface contact between the PCM and the substrate and insulating the substrate from air temperatures. Handmade LDPE bags were used as the PCM encapsulation method to wrap the perlite bag because of their low cost. However, the installation of the LDPE bags was more difficult than the installation of the PVC tubes or the $0.33 \mathrm{~L}$ bottles used in Experiments 1 and 2, respectively, which would increase installation costs if the design is not improved before its possible industrialization. 
406 The results showed that both PCM RT12 and RT15 provided thermal benefits of $1^{\circ} \mathrm{C}$ compared 407 with the control bag for the day that was selected as representative of the experiment. In the 408 case of the passive heating system with water (Figure $7-C$ ), the thermal benefits were less. 409 Specifically, an increase of only of $0.5^{\circ} \mathrm{C}$ was achieved at the coolest moment of the night in 410 the early morning.

411 Experiment 3 provided several improvements over Experiments 1 and 2. PCM RT15 was a 412 better candidate for the application because it melted and froze correctly. However, for RT12, 413 if $10^{\circ} \mathrm{C}$ was not achieved at night, it did not freeze at all; then its thermal benefits were limited. 


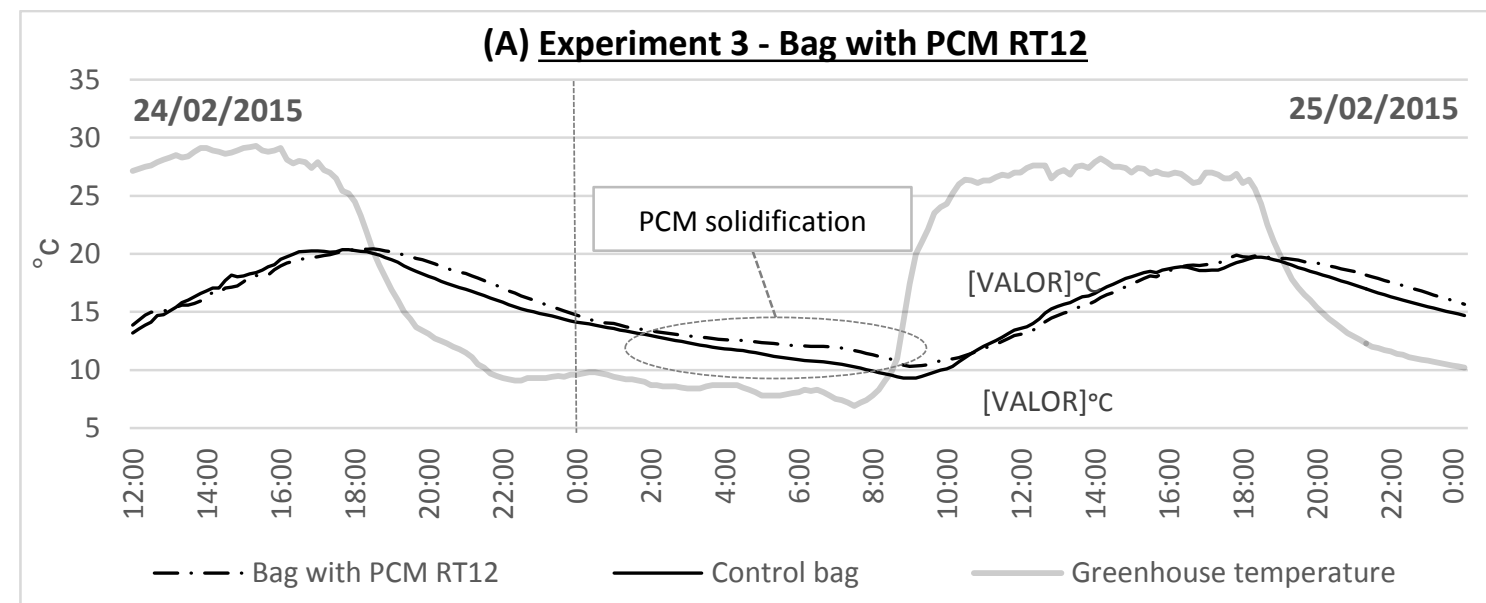

(B) Experiment 3 - Bag with PCM RT15

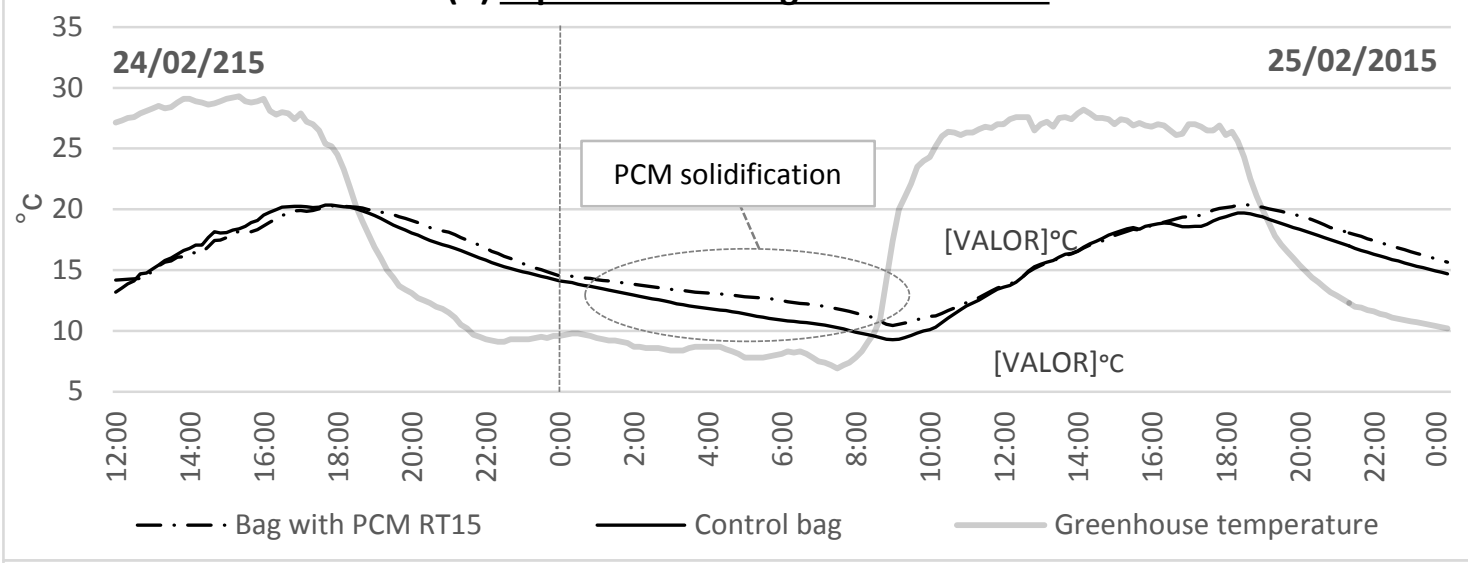

(C) Experiment 3 - Bag with added water

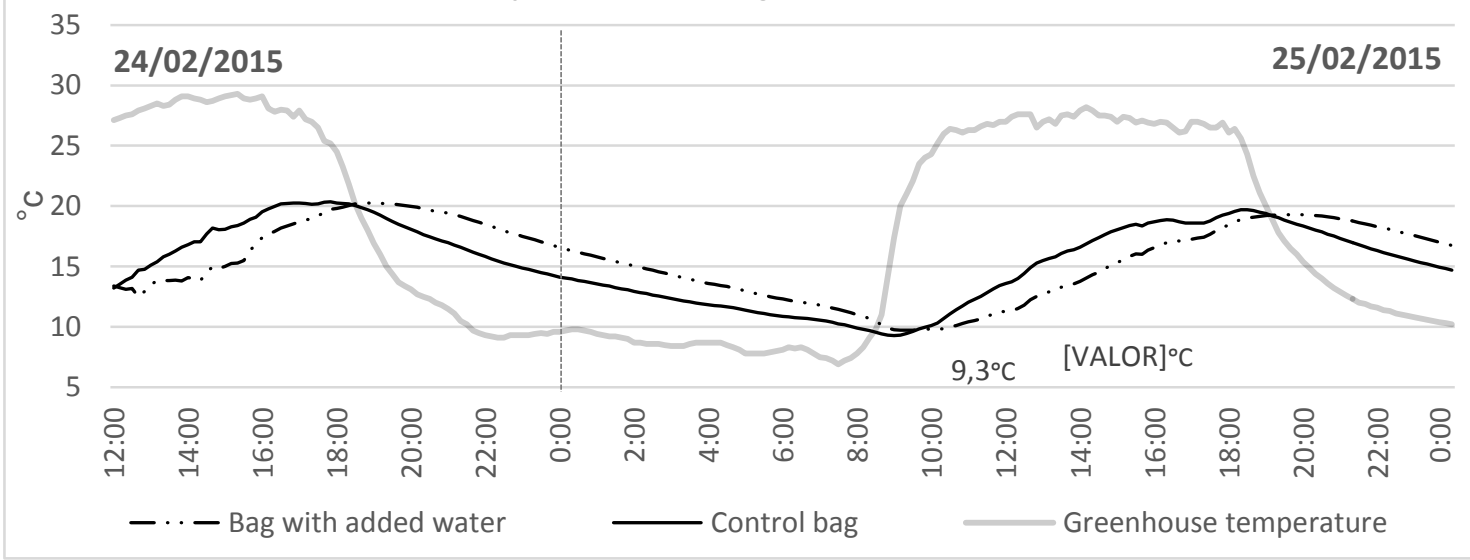

Figure 7. Diurnal temperature measurements of a control perlite bag and inner greenhouse temperatures in comparison with: (A) a root zone passive system with PCM RT12 wrapping the bottom of the perlite bag; (B) a root zone passive system with PCM RT15 wrapping the bottom of the perlite bag; (C) a root zone passive heating system with water wrapping the bottom of the perlite bag. Perlite temperatures were measured at the center of the bags. 
3.2.4. Experiment 4: Water, PCM RT15 and 12 wrapping the perlite entire bag.

Finally, based on the positive results obtained when the bottom of the perlite bag was wrapped with PCM, Experiment 4 was designed to analyze the thermal results when the perlite bag was completely wrapped (Table 2). This solution could lead to great heat loses to air as occurred in the experiments of Beyza Beyhan et al. [20]. However, this system maximizes the surface contact between the PCM and the perlite bag and insulates the perlite bag from greenhouse air temperatures. The installation of the PCM was laborious as for Experiment 3.

(A) Experiment 4 - Bag with PCM RT12

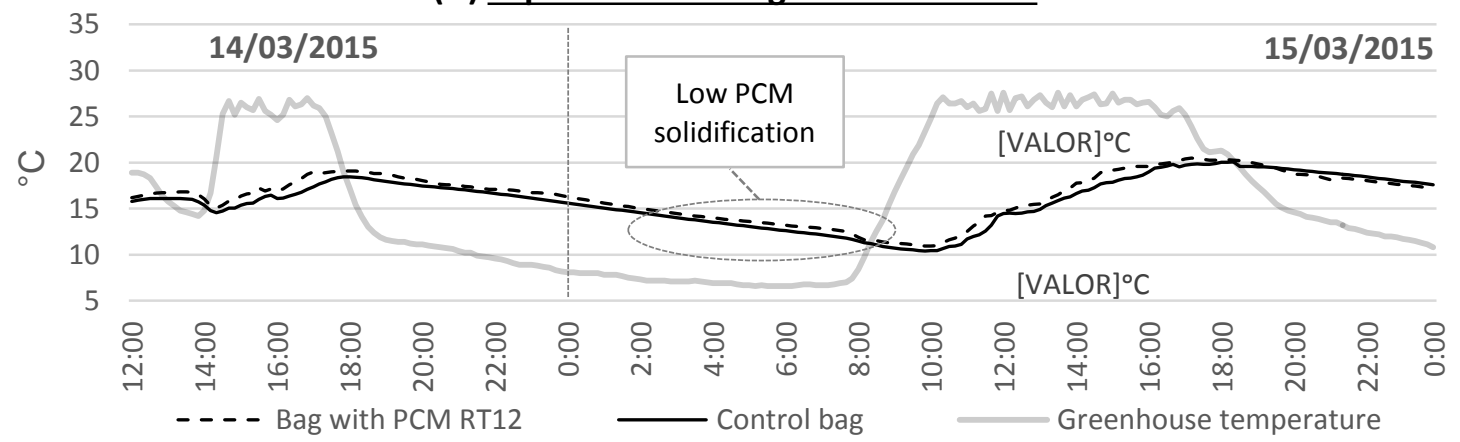

(B) Experiment 4 - Bag with PCM RT15

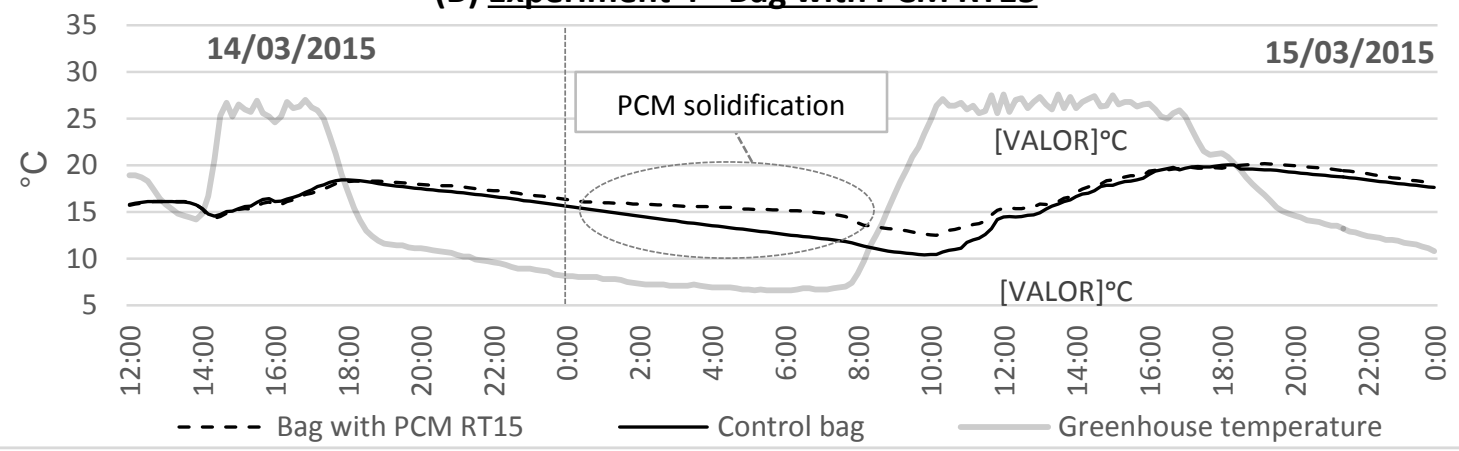

(C) Experiment 4 - Bag with added water

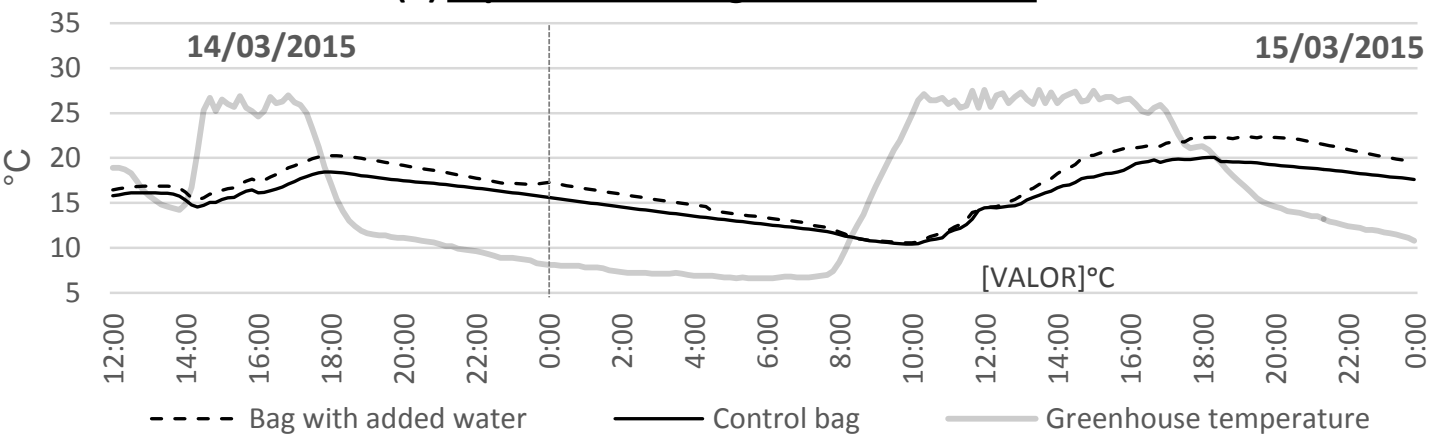

Figure 8. Diurnal temperature measurements of a control perlite bag and inner greenhouse temperatures in comparison with: (A) a root zone passive system with PCM RT12 wrapping the entire perlite bag; (B) a root zone passive system with PCM RT15 wrapping the entire perlite bag; (C) a root zone passive heating system with water wrapping the entire perlite bag. Perlite temperatures were measured at the center of the bags.

The results obtained during Experiment 4 (Figure 8) showed that PCM RT12 failed to freeze completely because temperatures below $10^{\circ} \mathrm{C}$ were not achieved. Consequently, the temperature difference with the perlite bag was lower than in Experiment $3\left(1^{\circ} \mathrm{C}\right)$. However, for the passive system with PCM RT15, the results were significantly better than in Experiment 3 (Figure 8). In Experiment 3, the temperatures of the perlite bag with the PCM RT15 passive 
system were between 0.5 and $1^{\circ} \mathrm{C}$ higher than those of the control bag. Nevertheless, in Experiment 4 this temperature difference increased to $1.5-2^{\circ} \mathrm{C}$. Unlike with PCM RT12, RT15 melted and froze correctly. Wrapping the perlite bag appears to be an effective solution to isolate the perlite bag from air temperatures and to increase heat exchange between the PCM and the substrate. However, this solution requires laborious installation. An improvement of the design, to facilitate installation, is required.

In the case of the water passive system (Figure 8-C) the daily temperatures of the substrate were higher than those of the control bag. Consequently, during the early night, the temperatures of this perlite bag were slightly higher but tended to equalize with the control bag temperatures in the morning. More water may have been needed to significantly increase the sensible heat of the perlite bag.

\subsection{Approximation of the potential energy and environmental savings.}

The experiment that provided the highest thermal benefits compared with that of the control perlite bag was the perlite bag studied in Experiment 4 (Table 2; Figure 8-B), which used RT15 PCM to wrap the entire substrate. Temperature data for one night was used to estimate a first approach of the potential energy and environmental savings that PCM could provide to root zone heating systems. From results obtained in section 3.1, 3.2 and 3.3. could be concluded that PCMs seem not to be a proper substitute for conventional root zone heating system. Nevertheless, PCM could be combined with existing heating systems to reduce their fuel consumption.

For the period in figure 8-B, when temperatures from the control bag were below $15^{\circ} \mathrm{C}$, with formula 2 was estimated that a total of $24.2 \mathrm{kWh}$ are required to maintain the control perlite bag at $15^{\circ} \mathrm{C}$ for a single night. The total energy that PCM RT15 provides to the perlite bag was $21 \mathrm{kWh}$ as calculated using formula 2. Therefore, at night, PCM RT15 provided the perlite bag with $86.7 \%$ of the total heat required to maintain the root zone at $15^{\circ} \mathrm{C}$.

473 Table 4 shows the equivalent $\mathrm{CO}_{2}$ emissions and costs $(€)$ that could be saved at night per 474 hectare of crop if PCMs were used as a tool to reduce fuel consumption from a conventional 475 gas, oil or biomass root zone heating system. As can be observed in Table 4, the oil heating 476 system could realize the highest environmental and economic benefits from the PCM because oil systems have the highest $\mathrm{CO}_{2}$ emissions and the highest price per $\mathrm{kWh}$ produced. The $\mathrm{CO}_{2}$ savings for the biomass heating system are very low. Pellets used as fuel are considered to be a byproduct from another system. Therefore, few emissions are accounted for in the process of obtaining of the pellets. For this scenario, the use of PCM for environmental savings would not make sense as the emissions from producing PCM would be too high to allow for sufficient emissions to be saved during the operation phase to compensate for the initial environmental impact from PCM installation. 
Table 4. Potential environmental and economic savings per hectare at night between 14/03/2015 and $15 / 03 / 2015$.

487

\begin{tabular}{|c|c|c|c|c|}
\hline & $\begin{array}{c}\text { Emissions generated to } \\
\text { maintain control bag } \\
\text { at } 15 \circ \mathrm{C} \\
\text { (kg CO} 2 \text { eq.) }\end{array}$ & $\begin{array}{c}\text { Emissions saved by } \\
\text { PCM } \\
\text { (kg CO} 2 \text { eq.) }\end{array}$ & $\begin{array}{l}\text { Fuel costs to maintain } \\
\text { the control bag at } 15 \circ \mathrm{C} \\
\qquad(€)\end{array}$ & $\begin{array}{l}\text { Fuel costs saved by } \\
\operatorname{PCM}(€)\end{array}$ \\
\hline Gas heating system & 25.4 & 22.0 & $129.70 €$ & $112.47 €$ \\
\hline Oil heating system & 34.7 & 30.1 & $160.34 €$ & $139.04 €$ \\
\hline Biomass heating system & 1.7 & 1.5 & $141.55 €$ & $122.74 €$ \\
\hline
\end{tabular}

488

489 According to the previous environmental and economic analysis completed [21], the annual

490 emissions generated per hectare by a PCM root zone temperature control system similar to

491 the ones studied in this article are approximately $962 \mathrm{~kg}$ of equivalent $\mathrm{CO}_{2} .89 \%$ of these

492 emissions are attributable to PCM production; a $10 \%$ are attributable to production of the

493 LDPE required to produce the LDPE bags used for the encapsulation of the PCM; the remaining

$4941 \%$ corresponds to emissions from waste management if PCM and LDPE are recycled. No

495 transportation emissions were accounted for in the previous study [21]. Maintenance includes

496 substituting the LDPE bags (a manual process that does not require energy consumption) for

497 new ones every three years, to avoid bag degradation and consequently possible PCM losses.

498 The emissions derivatives from this process were accounted for within the $10 \%$ of emissions

499 related to the LDPE bags.

500 In terms of costs, the annual investment per hectare of a PCM root zone temperature control

501 system is approximately $89,100 €$ [21]. $50 \%$ of the cost comes from the initial installation and

502 substitution of the LDPE bags every 3 years; $47 \%$ of the cost comes from the purchase of

503 PCMS; $1.5 \%$ of the cost comes from the acquisition of LDPE bags, and the remaining $1.5 \%$

504 comes from the daily maintenance[21].

505 Using the values described above, the number of days the PCM must be operative annually to 506 guarantee environmental and economic payback of the system were calculated. A lifespan of 50720 years for the whole system and PCM was assumed [21]. Table 5 shows these results. It must 508 be taken into account that this table shows a first approximation of the payback based on one 509 night temperatures (figure 8-b). Then, there is certain uncertainty in results. However, 510 environmental results show in this section draw first environmental and economic results 511 which could be used in the future to determine how the system under study may evolve.

512 Table 5. Required operation days/years of a root zone temperature control system with PCM to

\begin{tabular}{lcc} 
& $\begin{array}{c}\text { Required operation for } \\
\text { Environmental payback } \\
\text { (days/year) }\end{array}$ & $\begin{array}{c}\text { Required operation for } \\
\text { Economic payback } \\
\text { (days/year) }\end{array}$ \\
\hline Gas heating system & 43 days/year & 792 days/year \\
\hline Oil heating system & 32 days/year & 641 days/year \\
\hline Biomass heating system & 641 days/year & 726 days/year \\
\hline
\end{tabular}


515 Finally, it seems that PCM could be feasibly used to increase the efficiency of conventional gas

516 or oil root zone heating systems and to reduce the carbon footprint of such system, but such a

517 substitution may not be made for a heating system based on a biomass boiler. As mentioned

518 previously, emissions from biomass heating systems are so low that the $\mathrm{CO}_{2}$ emissions savings

519 obtained with the PCM would not compensate for the emissions from the production of the

520 PCM and LDPE bags. The use of recycled PCM and LDPE for encapsulation or an increase in the

521 efficiency of the PCM production process could lead to a reduction in the operation days/year

522 required to achieve environmental payback.

523 The results shown in Table 5 reveal that the application of PCM does not seem to be

524 economically viable until installation and PCM prices fall significantly.

525

\section{Conclusions}

- An appropriate melting and freezing temperature for a root zone passive heating system with $\mathrm{PCM}$ in Mediterranean greenhouses seems to be $15^{\circ} \mathrm{C}$. A melting/freezing temperature of $12^{\circ} \mathrm{C}$ does not ensure the freezing of the PCM if temperatures do not fall under $10^{\circ} \mathrm{C}$.

- The best PCM location for the application under study may be wrapping the perlite bag with the material to insulate it from air temperatures.

- PCM could be used to increase the thermal efficiency of conventional heating systems but PCM does not provide the substrate enough thermal energy to keep it above $15^{\circ} \mathrm{C}$. The use of higher quantities of PCM or PCMs with higher enthalpies should be studied.

- Based on one night results, PCM seem to offer potential to reduce the carbon footprint of gas and oil conventional root zone heating systems.

- In economic terms, based on one night results too, PCM do not seem to be a viable solution to improve the environmental performance of root zone heating systems.

540 - Further research should be conducted to more specifically study PCM behavior during an entire winter. Results from the study may also be used to increase the precision of the environmental and economic results from our study. 
The authors thank the Spanish "Ministerio de Economía y Competitividad" (MINECO) for financial support to the research project "Agrourban sustainability through rooftop greenhouse's, Ecoinnovation on residual flows of energy, water and $\mathrm{CO} 2$ for food production" (CTM2013-47067-C2-1-R), and the Catalan Government, La Generalitat de Catalunya, for awarding a research scholarship (FI-AGUAR 2015) to Pere Llorach Massana.

551

\section{References}

[1] L.F. Cabeza, a. Castell, C. Barreneche, a. De Gracia, a. I. Fernández, Materials used as PCM in thermal energy storage in buildings: A review, Renew. Sustain. Energy Rev. 15 (2011) 16751695. doi:10.1016/j.rser.2010.11.018.

[2] A. Castell, I. Martorell, M. Medrano, G. Pérez, L.F. Cabeza, Experimental study of using PCM in brick constructive solutions for passive cooling, Energy Build. 42 (2010) 534-540. doi:10.1016/j.enbuild.2009.10.022.

[3] C. Thiel, T. Stengel, C. Gehlen, Eco-Efficient Construction and Building Materials, Elsevier, 2014. doi:10.1533/9780857097729.2.368.

[4] T. Nomura, N. Okinaka, T. Akiyama, Waste heat transportation system, using phase change material (PCM) from steelworks to chemical plant, Resour. Conserv. Recycl. 54 (2010) 10001006. doi:10.1016/j.resconrec.2010.02.007.

[5] D. Mondieig, F. Rajabalee, A. Laprie, H.A.. Oonk, T. Calvet, M. Angel Cuevas-Diarte, Protection of temperature sensitive biomedical products using molecular alloys as phase change material, Transfus. Apher. Sci. 28 (2003) 143-148. doi:10.1016/S1473-0502(03)00016-8.

[6] S. Kooli, S. Bouadila, M. Lazaar, A. Farhat, The effect of nocturnal shutter on insulated greenhouse using a solar air heater with latent storage energy, Sol. Energy. 115 (2015) 217-228. doi:10.1016/j.solener.2015.02.041.

[7] H. Benli, A. Durmuş, Evaluation of ground-source heat pump combined latent heat storage system performance in greenhouse heating, Energy Build. 41 (2009) 220-228. doi:10.1016/j.enbuild.2008.09.004.

[8] A. Kürklü, Energy storage applications in greenhouses by means of phase change materials (PCMs): a review, Renew. Energy. 13 (1998) 89-103. doi:10.1016/S0960-1481(97)83337-X.

[9] H. Benli, A. Durmuş, Performance analysis of a latent heat storage system with phase change material for new designed solar collectors in greenhouse heating, Sol. Energy. 83 (2009) 21092119. doi:10.1016/j.solener.2009.07.005.

[10] A. Najjar, A. Hasan, Modeling of greenhouse with PCM energy storage, Energy Convers. Manag. 49 (2008) 3338-3342. doi:10.1016/j.enconman.2008.04.015.

[11] F. Berroug, E.K. Lakhal, M. El Omari, M. Faraji, H. El Qarnia, Thermal performance of a greenhouse with a phase change material north wall, Energy Build. 43 (2011) 3027-3035. doi:10.1016/j.enbuild.2011.07.020.

[12] A. Gosselin, M.J. Trudel, Interactions between root-zone temperature and light levels on growth, development and photosynthesis of Lycopersicon esculentum Mill. cultivar "Vendor," Sci. Hortic. (Amsterdam). 23 (1984) 313-321. doi:10.1016/0304-4238(84)90027-X.

[13] Y. Kawasaki, S. Matsuo, Y. Kanayama, K. Kanahama, Effect of Root-zone Heating on Root Growth and Activity, Nutrient Uptake, and Fruit Yield of Tomato at Low Air Temperatures, J. Japanese Soc. Hortic. Sci. 83 (2014) 295-301. doi:10.2503/jjshs1.MI-001.

[14] S. Adams, K.E. Cockshull, C.R.J. Cave, Effect of Temperature on the Growth and Development of Tomato Fruits, Ann. Bot. 88 (2001) 869-877. doi:10.1006/anbo.2001.1524. 
[15] Á. Calatayud, E. Gorbe, D. Roca, P.F. Martínez, Effect of two nutrient solution temperatures on nitrate uptake, nitrate reductase activity, $\mathrm{NH} 4+$ concentration and chlorophyll a fluorescence in rose plants, Environ. Exp. Bot. 64 (2008) 65-74. doi:10.1016/j.envexpbot.2008.02.003.

[16] D.A.G. Jones, I. Sandwell, C.J.W. Talent, The effect of soil temperature when associated with low air temperatures on the cropping of early tomatoes, ISHS Acta Hortic. 76 Symp. More Profitab. Use Energy Prot. Cultiv. (1978) 167-171. http://www.actahort.org/books/76/76_23.htm (accessed January 26, 2015).

[17] H.C. Thompson, R.W. Langhans, A.-J. Both, L.D. Albright, Shoot and Root Temperature Effects on Lettuce Growth in a Floating Hydroponic System, J. Am. Soc. Hortic. Sci. 123 (1998) 361-364.

[18] R.K. Atkin, G.E. Barton, D.K. Robinson, Effect of Root-growing Temperature on Growth Substances in Xylem Exudate of Zea mays, J. Exp. Bot. 24 (1973) 475-487. doi:10.1093/jxb/24.2.475.

[19] P. Growthl, The effect of temperature on plant growth, Annu. Rev. Plant. Physiol. (1952) 347362.

[20] B. Beyhan, H. Paksoy, Y. Daşgan, Root zone temperature control with thermal energy storage in phase change materials for soilless greenhouse applications, Energy Convers. Manag. 74 (2013) 446-453. doi:10.1016/j.enconman.2013.06.047.

[21] P. Llorach-Massana, J. Peña, J. Rieradevall, J.I. Montero, LCA \& LCCA of a PCM application to control root zone temperatures of hydroponic crops in comparison with conventional root zone heating systems, Renew. Energy. 85 (2016) 1079-1089. doi:10.1016/j.renene.2015.07.064.

[22] M. DORAIS, A. PAPADOPOULOS, A. GOSSELIN, Greenhouse tomato fruit quality, in: Hortic. Rev. Vol. 26, 2001: pp. 239-319.

[23] S. Grillas, M. Lucas, E. Bardopoulou, S. Sarafopoulos, M. Voulgari, Perlite based soilless culture systems: current commercial applications and prospects, Acta Hortic. (2001) 105-114. doi:10.17660/ActaHortic.2001.548.10.

[24] P.A. Putra, H. Yuliando, Soilless Culture System to Support Water Use Efficiency and Product Quality: A Review, Agric. Agric. Sci. Procedia. 3 (2015) 283-288. doi:10.1016/j.aaspro.2015.01.054.

[25] W.T. Bussell, S. Mckennie, Rockwool in horticulture, and its importance and sustainable use in New Zealand, 0671 (2015). doi:10.1080/01140671.2004.9514277.

[26] FAOSTAT, Food and Agriculture Organization of the United Nations database, (2015). http://faostat3.fao.org/ (accessed January 27, 2016).

[27] Generalitat de Catalunya, Ruralcat, (2015). www.ruralcat.net (accessed September 10, 2015).

[28] J. Pérez Parra, M.I. Cuadrado Gómez, Tecnologia de invernaderos II. Curso superior de especializacion, 1st ed., Junta de Andalucía, 1998. http://www.agricolajerez.com/tecnologiainvernaderos-ii-curso-superior-especializacion.

[29] Rubitherm Technologies GmbH, Rubitherm RT12 data sheet, (n.d.) 1. http://www.rubitherm.eu/media/products/datasheets/Techdata_-RT12_EN.PDF (accessed January 7,2016$)$.

[30] Rubitherm Technologies GmbH, Rubitherm RT15 data sheet, (n.d.) 1. http://www.rubitherm.eu/media/products/datasheets/Techdata_-RT15_EN.PDF (accessed January 7,2016$)$.

[31] Rubitherm Technologies $\mathrm{GmbH}$, Rubitherm RT18HC data sheet, (n.d.) 1. http://www.rubitherm.eu/media/products/datasheets/Techdata_-RT18HC_EN.PDF (accessed January 7,2016$)$.

[32] J. Bachmann, K.L. Adam, Organic Pumpkin and Winter Squash Marketing and Production, 2010. https://attra.ncat.org/attra-pub/summaries/summary.php?pub=30 (accessed April 2, 2015). 
[33] R. Orozco, O. Marfa, S. Burés, Water status of graded perlites, Acta Hortic. 401: Inter (1995) 7. doi:10.17660/ActaHortic.1995.401.16.

[34] ISO, ISO 14040, Environmental management - Life cycle assessment - Principles and framework, International Organization for Standardization, Geneve, 2006.

[35] Gas Natural Fenosa, Natural Gas Rates, (2016). http://www.gasnaturalfenosa.es/html/esp_neg/superplanes/index.html?id=es (accessed January 7, 2016).

[36] Spanish Institute for diversification and energy saving (IDAE), Studies, reports and statistics, (2014). http://www.idae.es/INDEX.PHP/index.php/idpag.802/relcategoria.1368/relmenu.363/mod.pags /mem.detalle (accessed January 7, 2016).

[37] S.A. of energy recovery from B. AVEBIOM, Pellets prices in Spain, (2014). http://www.avebiom.org/es/noticias/News/show/precios-del-pellet-en-espana-653 (accessed January 7, 2016). 